\title{
PhEMaterialist encounters with glitter: the materialisation of ethics, politics and care in arts-based research
}

Rebecca Coleman, Sociology, Goldsmiths, University of London, e- mail rebecca.coleman@gold.ac.uk Jayne Osgood, Centre for Education Research \& Scholarship, Middlesex University, e-mail j.osgood@mdx.ac.uk

\section{Abstract}

This paper re-turns to a workshop we co-organised in London in 2018 as part of a series called 'how to do sociology with...' (Methods Lab, Sociology Department, Goldsmiths, University of London). The series aims to consider what happens when the materials, media, objects, devices and atmospheres of social research central to our practices are brought into focus. The specific material that we worked with and thought through in this workshop was glitter - a thing that is ubiquitous in early childhood and in wider feminine, gay, and queer cultures. We draw on new materialist theories, methods and practice research to consider how preparing and dismantling this workshop might be understood as a means of enacting feminist new materialism. We do this not to propose a blueprint for how new materialisms should be done so much as to offer a series of questions, reflections, and diffractions on what unfolded and the affective and embodied traces that were left. In this sense, the paper understands arts-based practice to hold unanticipated pedagogical capacities which we attend to throughout the paper in terms of ethics, politics and care. We dwell upon ethics politics and care by drawing on long-standing feminist arguments regarding what is often neglected in written accounts of doing research and by focusing on the affective work involved in designing, choreographing, and managing a workshop that asked participants to seriousplay (Haraway, 2016) with glitter and explore its material and affective properties. We discuss our own discomfort with, and uncertainty about, organising such a workshop, and go on to outline what we see as the productive aspects and implications of 
orchestrating a glitter workshop for how we might conceive and do new materialist work. This includes a discussion about the response-ability of seriousplay with plastic in the contemporary climate, and more broadly about what new materialist methods and practice research might contribute to an understanding of educational and social research, and pedagogical and political practice. Throughout, photographs taken by us before, during, and after the workshop are included, to not only illustrate the points we make and give readers/viewers a different sense of the workshop, but also extend what might count as academic knowledge production and circulation.

Keywords: glitter, feminist new materialisms, methods, arts-based methods, practice research, pedagogy, ethics, politics, care

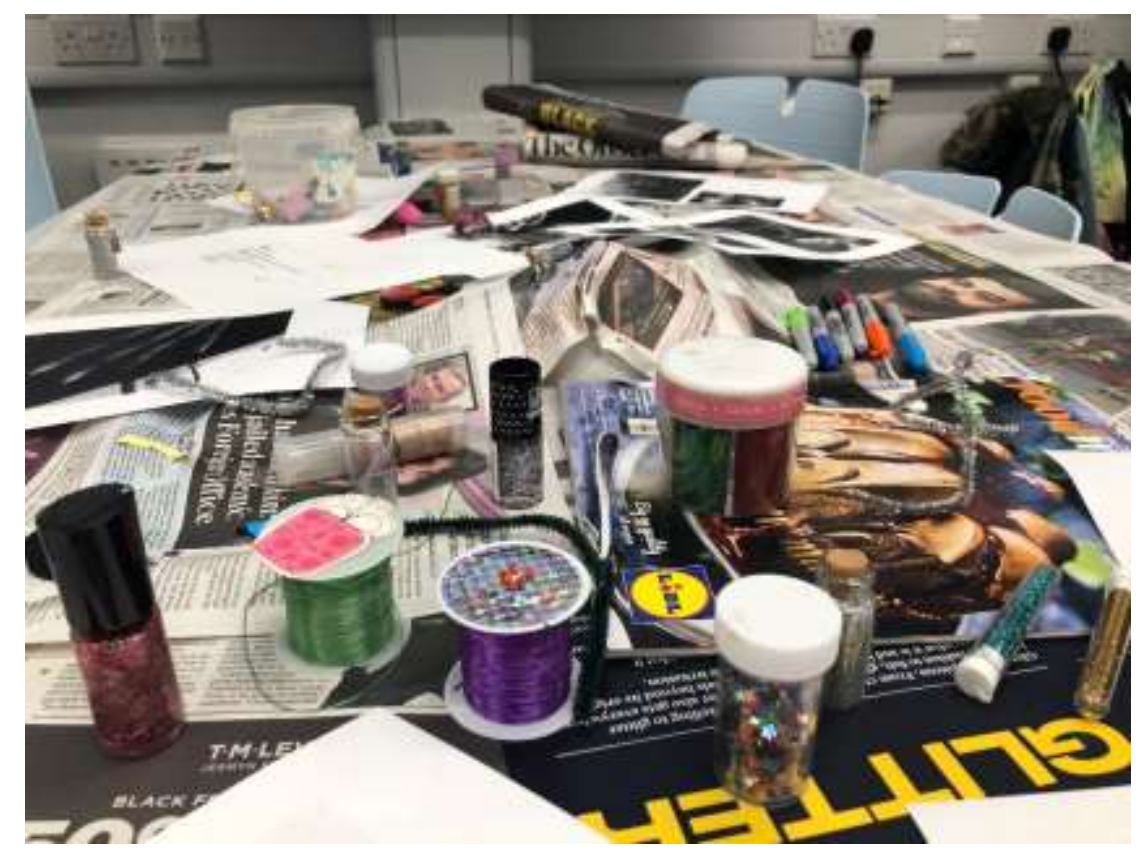

\section{Introduction: Materialising a Glitter Workshop}

This paper takes as its starting place a practice research workshop that we co-organised and ran. The affective labour involved in making the workshop happen, and the subsequent aftershocks, expanded our understandings of, and approaches to, feminist new materialisms. The workshop centred around glitter - a material that is ubiquitous in early childhood and in wider feminine, gay, and queer cultures, as well as in contemporary debates regarding plastics, pollution, and nature. We asked participants to work with various glitters in different ways, and to reflect on its material and affective properties as they were in the process of working with it. In other words, we asked them to explore not so much what glitter is as what it does. Understanding a material, or assemblage of materials, in terms of what it does/they do is core to new materialisms, as matter is dynamic, processual and transformative and as such, is not settled; it is always in the process of 
materialising and becoming. In this paper we contribute to this understanding of matter by exploring what glitter does. We also seek to make a further move to consider what we do with what it does. That is, this paper is an attempt to grapple with how to account for what glitter does - or, more specifically, what it did to us in the context of the workshop and the reverberations that are felt months later.

\section{Feminist Matters of Care}

We take this approach as a way to centre questions of ethics, politics and care, which we see as crucial overlapping issues in feminist new materialist work (for recent examples see Hickey-Moody, 2018; Ringrose, Warfield \& Zarabadi 2018; and Renold \& Ringrose, 2019) and in longer standing work on the doing of feminist research. Our aim here, then, is to connect up ongoing feminist arguments that emphasise how research methodologies and practices are necessarily political and ethical activities (e.g. Stanley and Wise, 1982; Skeggs, 1995; Ryan-Flood and Gill, 2010; Gunaratnam and Hamilton, 2017), with more recent arguments developed in the context of feminist new materialisms concerning knowledge production, participation, and care (e.g. Langford, 2019; Hodgins, 2019; Osgood \& Robinson, 2019).

Throughout, we pay attention to the materialities and affects involved in organising, running and participating in the workshop. We include reflections on our own and some of the other human participants' affective experiences of the workshop, and we also include some photographs taken by ourselves and workshop participants on our mobile phones that capture various moments, from our preparations to what was crafted, as a means to acknowledge the co-constitution of knowledge and practice. In doing so, we aim to make clear(er) what are often the hidden feelings and labour of academic work. We follow Roisin Ryan-Flood and Ros Gill (2010: 1) in 'locat[ing] ourselves within an ongoing tradition of feminist "troubling" of the taken for granted in research' and of 'the ways in which secrecy and silence matter - ethically, politically and epistemologically'. We also draw on the question asked by Maria Puig de la Bellacasa (2017: 39): 'How are critical people, in particular researchers, thinkers, and theorists involved in the making of the world?'. In responding, she suggests that:

As blurred boundaries deepen entanglements and interdependencies, the ethico-political demand persists and maybe intensifies for elucidating how different configurations of knowledge practices are consequential, contributing to specific rearrangements. Even more than ever before, knowledge as relating - while thinking, researching, storytelling, wording, accounting - matters in mattering of worlds (2017: 28).

Puig de la Bellacasa argues here that understanding the worldmaking of knowledge practices requires an attention to and cultivation of care, where care 'engages much more than a moral stance; it involves affective, ethical, and hands on agencies of practical material consequence' (2017: 4). She also notes the ways in which humans - the critical people she focuses on - are always in entangled and interdependent relations with other humans and non-humans. 
In this paper we explore ethics, politics and care in terms of the 'hands on agencies of practical material consequence', and the 'deep[...] entanglements and interdependencies' that Puig de la Bellacasa (2017: 28) identifies. In the first section of the paper, we discuss the workshop in terms of what we did, why and how, taking up Donna Haraway's (2016) concept of seriousplay and drawing attention to the plethora of human and non-humans that were involved in it. We do this as a means of opening up who might be considered to participate in research. We also seek to open up what might be considered to participate in research by examining the ways in which social science research might understand and work with nonhuman things. We understand glitter, and a variety of other materials, as agentic and, along with Jane Bennett (2010:21) and others, think that:

A lot happens to the concept of agency once nonhuman things are figured less as social constructions and more as actors, and once humans themselves are assessed not as autonomous but as vital materialities.

The second section builds on this approach to vital materialities to consider the affects that the human and non-human relations of the workshop generated. Here, we show how attending to these relations and affects is a means of making apparent that which is often overlooked in research processes, seeing this as a way to begin to open out what counts as ethics, politics and care in the doing of research and pedagogy. This section is divided into three sub-sections, each of which focuses on some of the specific affects generated in us and other human participants through the glitter workshop, including feelings of guilt and anxiety and our heightened sensibility to current debates about the environmental impact of glitter, which coalesced around biodegradable glitter, water bottles, and cloth and plastic bags. In the second section, we focus most clearly on what happened prior to the workshop itself. The third section carries through our concern with affect and materiality, this time with an inflection on what happened in, and immediately following, the workshop. We discuss setting it up and some of the processes and practices of making. In conclusion, we offer some reflections on ethics, politics, care, and pedagogy, exploring in particular some of the knotty questions that the workshop raised and what might be learnt from, as Haraway puts it, 'staying with the trouble'. For us in this paper then, 'staying with the trouble' involves not so much the resolution of the ethical and political questions that the workshop raised for us but rather an attention to their processual and situated character (Haraway 1997, Coleman 2008, Osgood, forthcoming). 


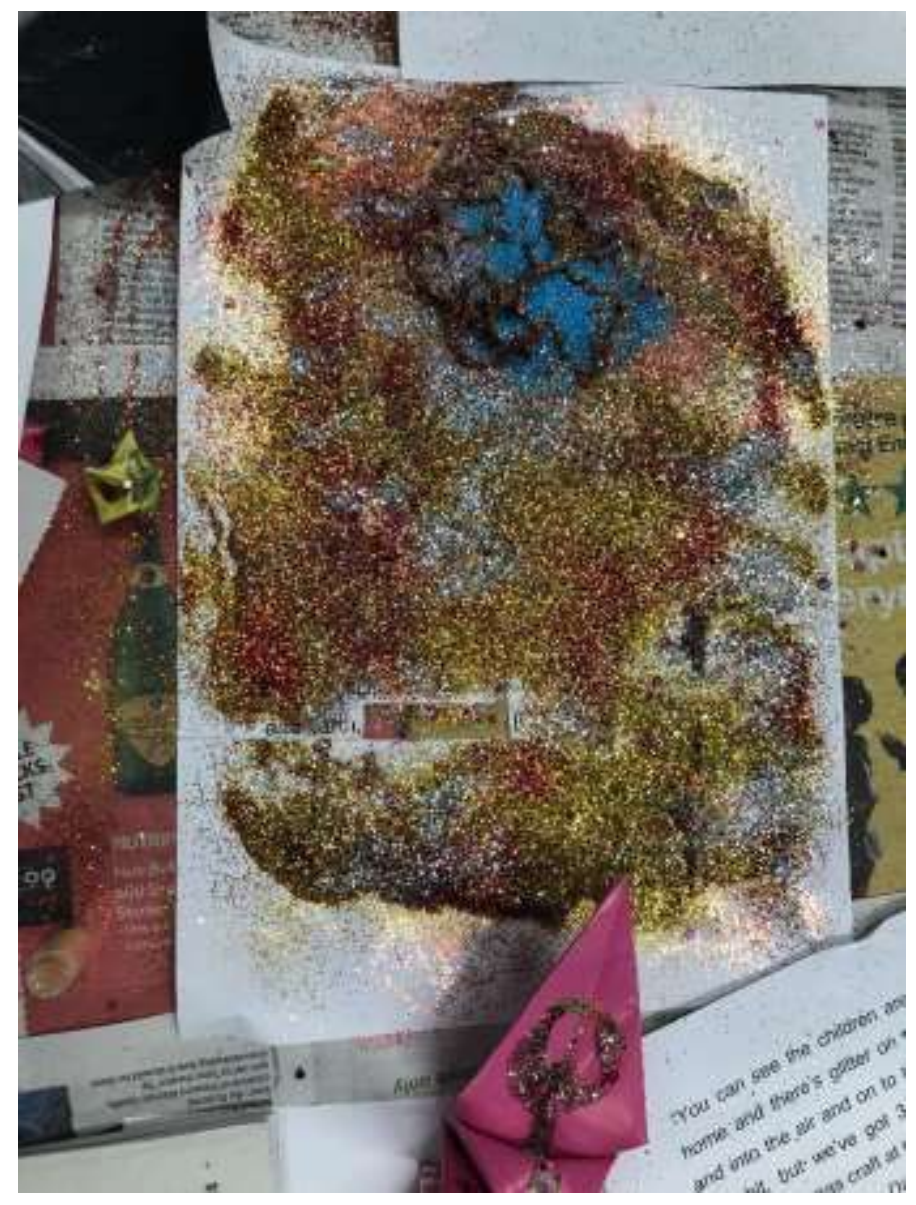

\section{Glitter's Invitation to Seriousplay}

We came to organise a workshop together on glitter as we have both, separately, been working with it. Jayne (Osgood, 2019) has focused on glitter as a means to disrupt and reunderstand the hegemony of developmentalist logic that shapes early childhood curriculum, arguing that taking glitter not as superficial, frivolous, and messy, but as agentic, underscores the importance of an entangled sensibility that demands a heightened ethics of responsibility in our research, pedagogical, and world-making practices. Beckie (Coleman, forthcoming) has followed glitter as it moves across and makes different worlds, including how young women imagine their futures, vagazelling ${ }^{1}$, films, and LGBTQ* activist glitter bombings, also arguing for an appreciation of glitter's vibrancy and of how ethics, politics and futures are created through human and non-human relations. Our work thus shares a feminist new materialist commitment, which we develop in terms of a concern with gender, sexuality, age, and race. We are also involved with various initiatives regarding how new materialisms might re-shape methodological practices (Osgood \& Robinson, 2019; PhEMaterialism, 2019; Coleman, Page and Palmer, 2019). Indeed, the glitter workshop was part of a series run by the Methods Lab, Sociology Department, Goldsmiths, called 'How to do sociology with...'. The series aims to centralise materials, media, objects, devices and 
atmospheres within social research and to consider what happens when these things are taken seriously.

\section{Engaging in World-Making Practices with Glitter}

We designed the workshop as an invitation to seriousplay (Haraway, 2016) with glitter and explore its material and affective properties. Haraway defines play in relation to her understanding of companion species, arguing that 'who is/are to be in/of the world is constituted in intra-and inter-action. The partners do not precede the knotting; species of all kinds are consequent upon worldly subject- and object-shaping entanglements' (2016: 13). Haraway's focus is on companion species as animals of various kinds. In our workshop, we broadened this focus to explore glitter as a material through which 'subject- and objectshaping entanglements' are worlded. Engaging in world-making practices with glitter during this workshop insisted that we recognise our situatedness as part of knowledge production, which in turn extended to the other human participants. As part of our careful choreography of the event we capped registration at 25 people; this number was reached very quickly. Ultimately 18 people, excluding ourselves, came to the workshop. Human participants included MA and PhD students, Early Career and more established scholars. The workshop was structured in such a way that all human participants were invited to work with the full range of different glitter and materials we provided.

\section{Encountering Different Glitter Differently}

We brought three different types of glitter to the workshop, we categorised the different glitter as 'natural', 'new' and 'recycled'. We arranged these different glitters on three separate tables. The 'natural' glitter, purchased from Amazon, was described as biodegradable cosmetic glitter for the face, body, hair and nails. On the table with this glitter we placed other 'natural' materials including leaves, shells, stones and string. The 'new' glitter had been purchased by Beckie for the workshop and other events and was brightly coloured. The recycled glitter came from Jayne's home and included glitter glue, glitter nail varnish, as well as half-full pots of glitter, and was arranged with other materials including pipe cleaners, sequins and an old copy of the British broadsheet newspaper The Guardian, which had been graffitied on by one of Jayne's children.

Glue, scissors and copies of the free tabloid newspaper The Metro, which we had both collected on our travels on public transport, were placed on each of the three tables. We asked participants to gravitate towards the table which most appealed to them, and gave them minimal instructions on what to do, other than suggesting they could work individually or in groups. We also let them know that after 25 minutes we would ask them to move to another table, leaving their creations on their original table for others to work on. They would work their way round all three tables before finishing on the table at which they had begun. 


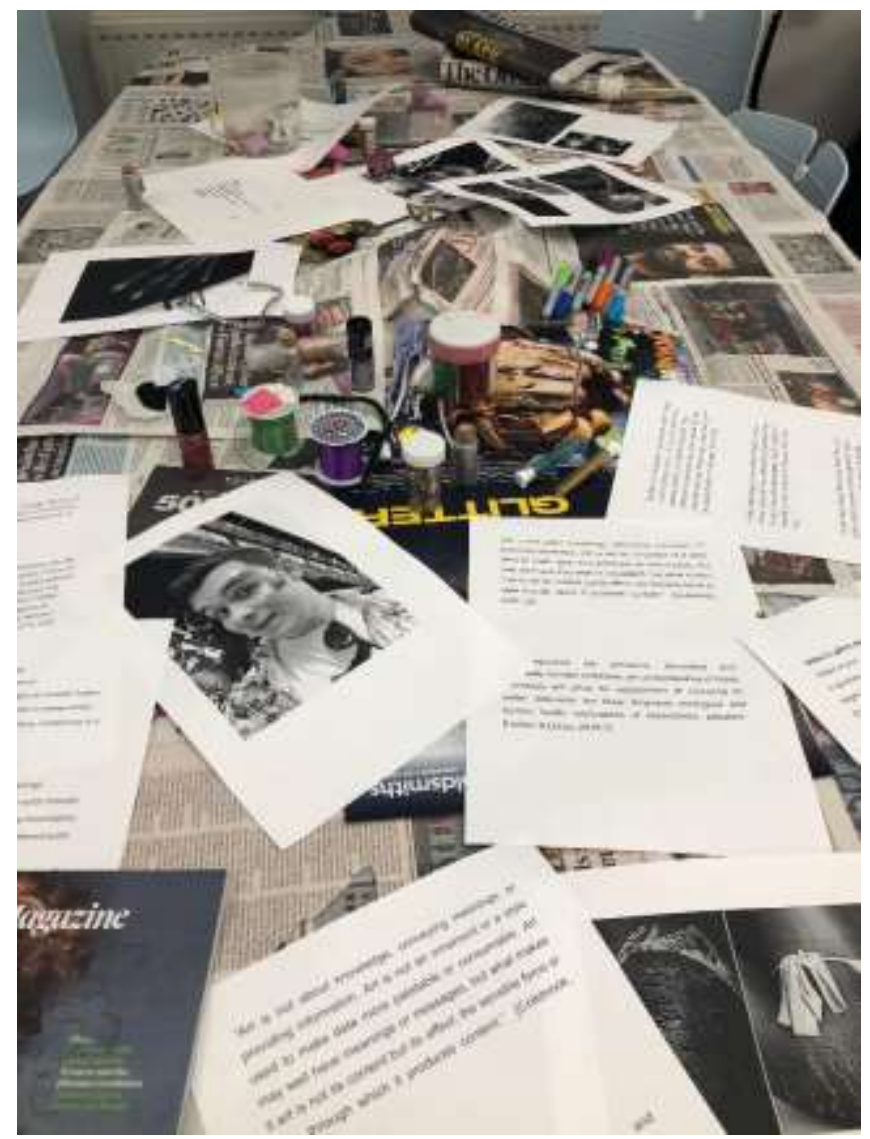

\section{Choreographing Matter, Bodies and Time to Produce Affective Patterns}

In planning the workshop, we had felt that a degree of choreography of materials, humans and time was necessary. We wanted to keep the workshop relatively open, to allow for the unexpected and unanticipated to emerge through the doing/making of/with glitter, and we were also curious about how different glitter might produce different affective patterns of engagement and disengagement, and of making/doing. That is, we wondered whether the glitters might be variously vibrant to different people, might provoke particular associations with the other materials they were assembled with, and might afford ways of working with them that were specific to these qualities. The structure of participants moving tables and working on pieces that others had created emerged from methods often used in early childhood classrooms (Moyles, Adams \& Musgrove, 2002), and Jayne had also participated in a workshop organised in such a way. It had prompted her to ask questions, including how she felt about others working on 'her' creation, whether or not this structure disrupts an individualised mode of making, and how our endless relationalities play into our worldmaking practices (Haraway, 2016). We were thus curious to see how participants in our workshop responded to our invitation to seriousplay with glitter. We also understood the structuring of the workshop in these ways in terms of feminist new materialist work. For example, in asking people to consider which of the tables most appealed to them, we understood the materials, and the tables, as vibrant and lively; as Bennett argues, materials 
have the capacity to 'act as quasi agents or forces with trajectories, propensities, or tendencies of their own' (2010: viii), demonstrating what she calls 'thing-power', or the 'strange ability for ordinary, man-made items to exceed their status as items and manifest traces of independence or aliveness' (2010: xvi). In explaining her understanding of 'thingpower', Bennett develops an account of human/non-human affective relations, arguing that things may not only be brought to life by humans, but might themselves generate affects in humans. In the organisation of the workshop, then, we understood the materials as, potentially, inviting people, demonstrating the intra-action between humans and nonhumans.

\section{A Game of Cat's Cradle: Seriousplay with Glitter}

Haraway's version of play is helpful to develop this understanding of human/non-human relations further. One of the ways in which Haraway explicates her notion of play is through the game of cat's cradle, where players, or participants, make string figures by passing loops of string between their fingers, with the potential to pass it back and forwards between two or more other participants. Haraway (1994) explains that:

Cat's cradle is about patterns and knots; the game takes great skill and can result in some serious surprises. One person can build up a large repertoire of string figures on a single pair of hands; but the cat's cradle figures can be passed back and forth on the hands of several players, who add new moves in the building of complex patterns. Cat's cradle invites a sense of collective work, of one person not being able to make all the patterns alone. One does not "win" at cat's cradle; the goal is more interesting and more open-ended than that. It is not always possible to repeat interesting patterns, and figuring out what happened to result in intriguing patterns is an embodied analytical skill (1994: 68-69).

The mode of engagement we asked of participants in the workshop, to seriousplay with glitter, was similarly concerned with the creation of collective and open-ended work. We organised the workshop not to ask participants to create the best piece of work that they could, nor to reflect on specific issues. We were interested not only, or not so much, in the content of what was produced in the workshop - was it good? What did it tell us? How could we interpret it? - as with the material and affective processes of working with glitter in a university classroom for a few hours. We are viewing ourselves and the human and nonhuman participants at the workshop as entangled with the world. Our participation in making/doing can be conceptualised as practices of worlding (Haraway, 2016; Stewart, 2017, Osgood \& Andersen, 2019). Worlding is a blend of the material and semiotic that complicates boundaries between subject and environment. It requires an attunement towards the generativity of an emergent world. Worlding insists that researchers become caught up in doings that in turn invites a sense of curiosity about the processes and the unanticipated that gets produced. Or, as Puig de la Bellacasa (2017: 31) states: 
Human intervention does not disappear, but agency is distributed. Interests and other affectively animated forces - such as concern and care - are decentred and distributed in fields of meaning-making materialities: from being located in the intentionality of human subjectivity, they become understood as intimately entangled in the ongoing material making of the world.

It was the ongoing material making of the world, and what alternative stories might be generated from becoming-with glitter, that was of interest to us.

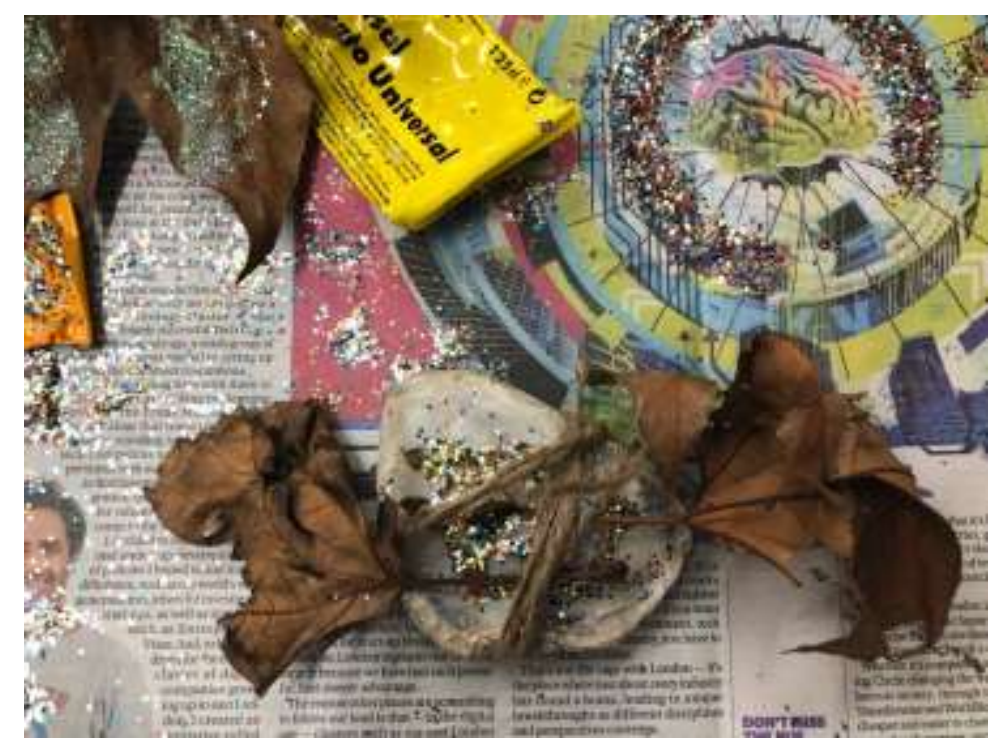

\section{Making the Unacknowledged Visible: Glittering Affects}

One of the ways in which we tried to elicit and attend to the material and affective qualities of glitter was in how we asked participants to introduce themselves by briefly commenting on something of their relationships with glitter and what had drawn them to the workshop. Some recounted strong connections to glitter, others were more ambivalent or uncertain, and others talked of their and others' hatred of it. For example, a woman boxer and academic spoke of how female boxers often wore glitter shorts in the ring, entangling challenging idea(I)s about gendered strength and violence with frivolous femininity. Others talked about their experiences and association of glitter with LGBTQ* clubbing and fashion. Another established feminist and critical race studies scholar talked about wanting to subvert age-appropriate activities, where glitter was seen as the exclusive preserve of the young and frivolous. A PhD student with a background in early childhood pedagogy hinted at the intense domestic labour involved when glitter is included as an art resource. It seemed that without exception, glitter does something; it provokes, agitates, and sets in motion a raft of affective flows and forces within the workshop. 


\section{When Glitter Works on the Feminist Researcher: Noticing Materialities}

We also reminded ourselves to pay attention to what we were feeling about the workshop, considering this both pedagogical, in the sense of what we were learning through doing, and political, in the feminist sense that Ryan-Flood and Gill (2010: 1) point to, in 'demanding that the unseen and the unacknowledged be made visible and heard'. Part of this work was noticing the materialities through which the workshop was planned, curated, run and written about. Many digital technologies made the workshop possible, again indicating the broad range of human and non-human material entanglements through which making/doing happens. For example, we purchased materials from Amazon - a corporation notorious for its poor working conditions, packaging practices, and tax-paying procedures. We publicised the workshop through emails to our respective institutions and networks as well as on social media (Twitter and Facebook), and asked people to register via an online events website, Eventbrite. As with Amazon, these are all companies that profit from users' data and which are frequently subject to boycotts; the ways in which they are now part of the infrastructures of contemporary academic events generated low-level though significant unease and ambivalence in us. Should we boycott them? How might we organise events without them, now? In what ways and with what affects/effects do these questions rely on a politics and ethics based on human intentionality, which is complicated, if not solved, by the approach that we are trying to elaborate ${ }^{2}$

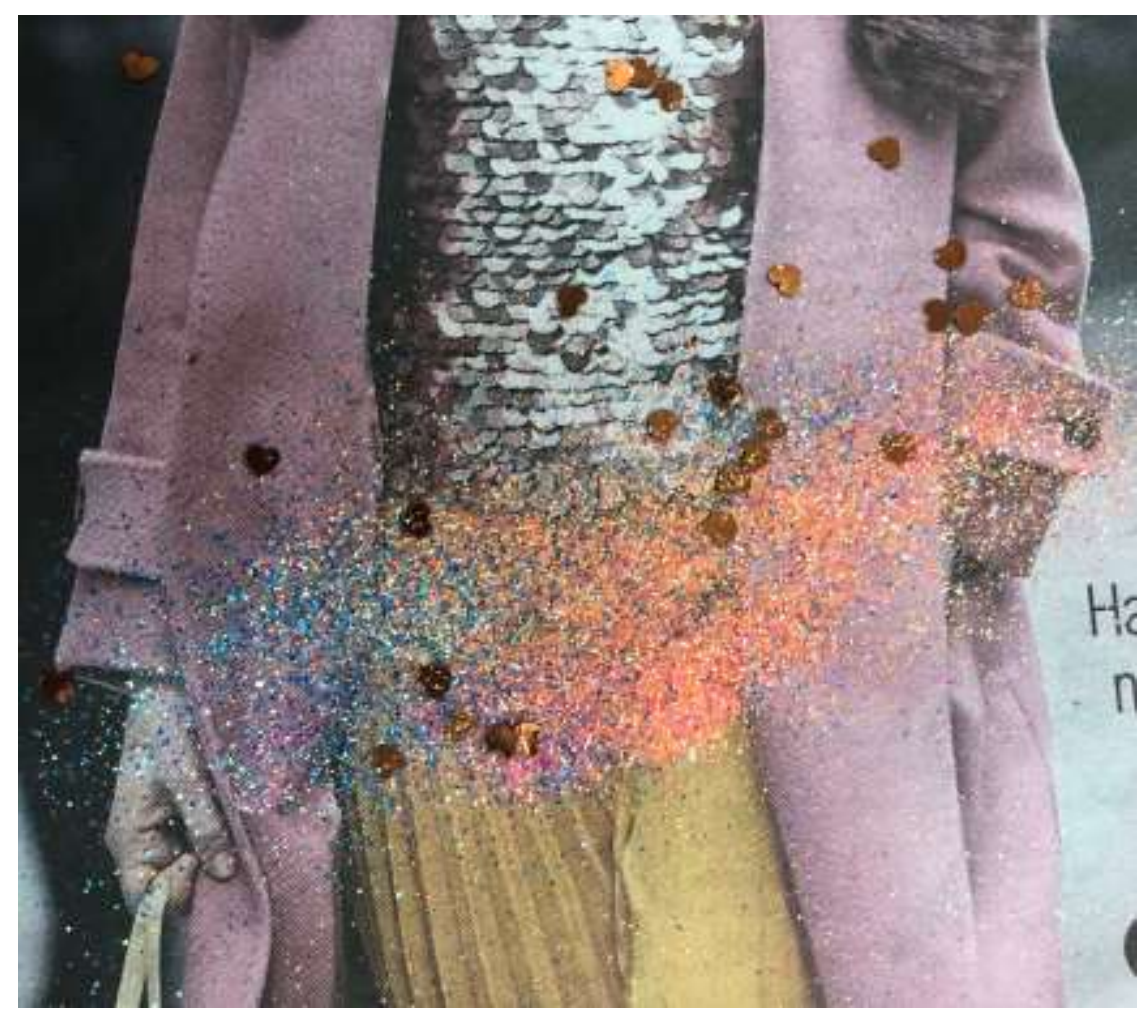

The registration process itself generated feelings of anxiety and disappointment in Beckie because fewer participants attended than had registered. She didn't want the workshop to be a drain on Jayne's time and energy. We planned the workshop through meeting on the 
day itself, and through prior emails and a Facebook Messenger call, hastily arranged once it became apparent that the Skype software on Beckie's work computer was not up-to-date. The planning of the workshop was both careful and came with the feeling of being rushed, of there not being enough time. Something similar might be said of the writing of this paper: it would be different, better, were there enough time in between the grant applications, marking, and other commitments that we are engaged in at this moment. During the writing of it, as plans changed and new work tasks were asked of us, we found ourselves, via marginalia comment boxes and emails, expressing our guilt at the work the other was doing on the paper, worrying that we weren't pulling our weight and that the other person was doing more.

\section{Attending to Life within the Contemporary Academy}

Gill (2010) argues that it is important from a feminist perspective to broaden 'the parameters for reflexivity' so they are not 'bounded by the individual study, leaving the institutional context in which academic knowledge is produced simply as taken for granted backdrop' (2010: 229). She notes the significance of her privileged position as a senior academic employed on an ongoing or 'permanent' contract, that makes the argument itself difficult and generates a range of affects, including guilt and shame. However, she reflects on how these affects 'can become a silencing dynamic, allowing us only to speak of extremes of injustice and suffering, as if the mere fact that others "have it worse" disentitles one from any kind of criticism, from saying anything about our own experiences' (Gill 2010: 228). Thus, she argues, to attend to the 'exhaustion, stress, overload, insomnia, anxiety, shame, aggression, hurt, guilt and feelings of out-of-placeness, fraudulence and fear of exposure within the contemporary academy' (2010: 229), is to 'make links between macroorganisation and institutional practices on the one hand, and experiences and affective states on the other, and open up an exploration of the ways in which these may be gendered, racialised and classed' (Gill 2010: 229).

\section{Good, Better, Best Glitter Relationalities}

The links between macro-organisational and institutional practices and differently structured experiences and affects became apparent to us in other ways as well, which continued to draw our attention to the materialities involved in the workshop. In response to one of Jayne's postings on Facebook publicising the workshop, concerns were expressed at the environmental effects of plastic glitter; and a suggestion that we should work with biodegradable glitter was presented. A link to a recent Guardian article about the negative effects that glitter has on the natural environment was posted as a means to support these concerns (the current moral panic surrounding the monstrousness of glitter meant that a link to any number of newspapers could have been posted). In response to this, Jayne posted a link to her recent chapter on glitter (Osgood, 2019) on Academia.edu, the online platform where academics can share publications, leading to a surge in views and downloads. These various machinations bring to the surface the tensions that shape life as 
'an enterprising neo-liberal subject' (Davies, 2007) in the 21st century academy, replete with concerns for impact, and the significant role that the more-than-human algorithms underpinning social media play in generating impact that is both immediate and measurable. In the publication, Jayne follows the thread of glitter from childhood art practices in the UK to various sites, including mica mines in India through which environmentally-friendly glitter can be produced. Many of these mines are illegal and are worked in by children, some of whom develop pneumoconiosis, a debilitating lung infection that can take up to 40 years to manifest. While this example does not refute or resolve the problem of plastic glitter on the 'natural' environment, it does highlight other political and ethical questions that emerge from it, such as the colonial, gendered, and aged processes through which sustainable glitter is made.

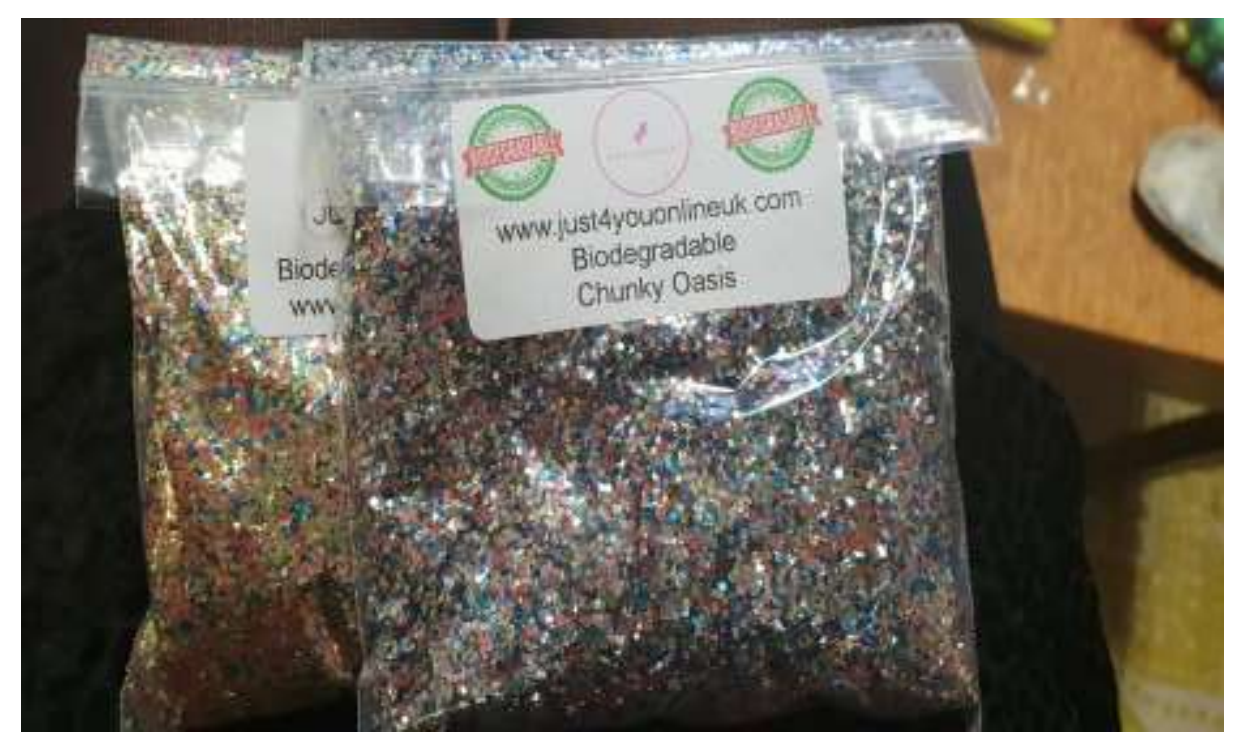

A combination of this Facebook post and emails that Beckie received inquiring about whether biodegradable or plastic glitter would be involved in the workshop generated a heightened sensitivity to the justifiable environmental furore surrounding glitter at this historical moment. For instance, the potential purchase of bottled water immediately prior to the workshop became an ethical dilemma. We stood frozen in the middle of a shop - what would a bottle of water designed for single use do in the assemblage of this workshop? Beckie had a reusable bottle with her, and Jayne then bought a Goldsmiths branded reusable metal water bottle as an alternative to the plastic bottle. This reusable water bottle adds to her already huge and growing collection and raises questions about environmental consciousness and how we potentially sense a 'response-ability' (Barad, 2007) within each material-discursive-semiotic encounter (as well as the environmental question of one person having 20 plus reusable bottles!). 


\section{Bags Matter: Natureculture Conundrums}

Our sensitivity to environmental response-ability extended to also include the bags in which we would carry the glitter and other workshop materials to the workshop room. In Beckie's office, we divided the glitter and other materials into three piles to coincide with the three tables - 'natural', 'recycled', and 'new'. Jayne had a cloth bag acquired from a French boulangerie whilst on a family holiday. This all-too familiar bag was laden with 'natural' artefacts gathered from the front garden: seashells, sticks, leaves, sharp stones, round pebbles; more 'recycled' materials from her daughter's art box: glue, glitter, sequins; and then on the way to Goldsmiths, copies of The Metro gathered from within the tube carriage. The bag is constantly repurposed: fragrant freshly baked croissants; wet swimming suit and towel; clothes destined for the charity shop; and... routinely stowed in the bottom of a handbag to avoid the unnecessary purchase of plastic carrier bags. Beckie had a number of such large plastic 'bags for life', purchased from supermarkets, which have been and continue to be reused. The bags came to both act as cultural signifiers on multiple levels and generate a range of affects in us, in that they drew us towards certain pasts and made us discuss whether it was appropriate to take plastic bags into the workshop; while recycled, they do not signal 'environmentally friendly' as material bags do. But where had the material bag been made? By whom? Under what conditions? What other stories might it have to offer? The bags were working on us in unanticipated and discomforting ways, and it was not clear to us - then or now - whether there was a distinct, neat or final response to these feelings and questions. 


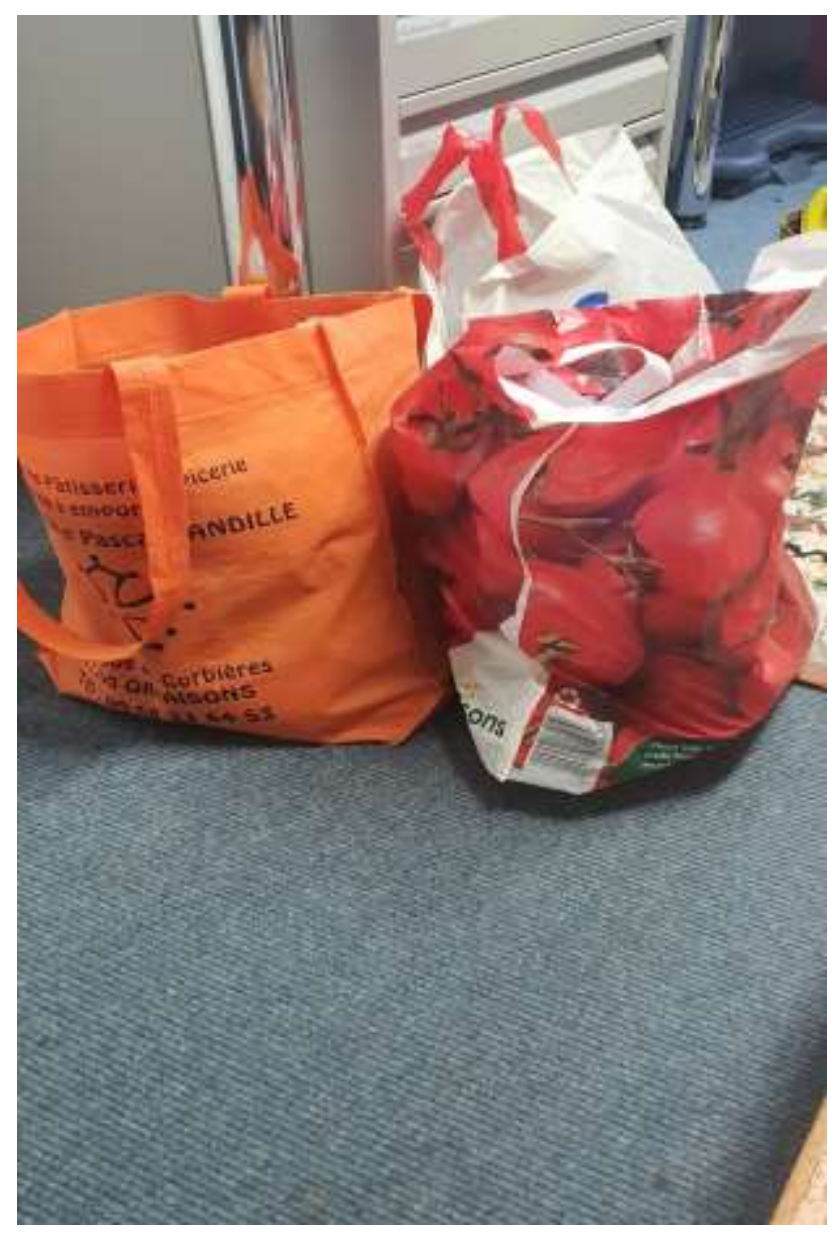

Indeed, as noted above, we discuss these issues here not to deflect from crucial concerns about the effects of plastics (bottles, bags, and micro-plastics that include glitter) on the environment, but rather to consider how our workshop, conceived as a means of exploring feminist new materialist approaches to materials and methodologies, generated a huge range of affects, as well as ethical and political trouble. To return to Haraway's (2003) work, cat's cradle is one of the string figures she develops in order to think nature and culture together: natureculture. Joanna Latimer and Mara Miele (2013) explain that:

The term natureculture was coined by Haraway as a provocation for collapsing and transgressing the dominant metaphysics that dichotomises nature and culture, and through which culture and all that is human is constituted as discontinuous with the rest of the world. As Haraway points out, nature cannot stand outside of culture, just as culture cannot stand outside of nature. This is because the meaning of nature - what we identify as natural - is not just determined by culture but is also the result of specific historical, material and political conditions of possibility. What humans identify as natural (claims, for instance, that women are naturally more caring or that people are 
naturally heterosexual) is an effect of culture, but culture naturalised

(2013: 11).

Interestingly for our focus in this paper on materiality and affect, Latimer and Miele argue that Haraway's work focuses particular attention on 'the affective dimensions of human/non-human relations as a critical challenge to dominant knowledge practices' (2013: 7). Defining affect in terms of attachment and being moved (2013: 8), they note that 'the shift to the natureculture perspective lets us see, first, how there is no "nature" that is not touched by what humans do as well as think and, second, that there is no part of being human that is unaffected by its material interaction with other materialities' (2013: 16). Importantly, understanding natureculture in terms of affect offers a way of seeing the world that complicates scientific research "whereby it is only the "effect" of one part on another that is studied [...]. This predilection is largely attributable, in a circular fashion, to the importance of measurement in science - since it is effects alone that are deemed to be measurable' (2013: 22). The concern about the impact of plastics such as glitter on the environment might be understood in terms of this framing. Nature is seen as a sphere separate to culture, into which culture intervenes, and pollutes. This is seen as a measurable effect. This view is certainly not wrong. What it does not account for, though, are the ways in which nature and culture are always-already intertwined and entangled. They affect each other.

It is clear that before the workshop is even underway we find ourselves caught up in a raft of ethical, political, feminist dilemmas brought about by our engagements with glitter. Whilst feminist new materialism heightens our sensitivities, it also invites us 'to stay with trouble' (Haraway, 2016) that is churned up and then go on to recognise that dwelling upon glitter as an ecology, and what glitter generates, holds the potential to push our investigations in unanticipated directions that are never in search of neat solutions. This mode of being in the world is deeply ethical but always speculative. It requires that we become attuned to sensations, things, places and spaces.

\section{Generating Situated Knowledges from Making: The Unruliness of Glitter}

Our encounters with glitter take us to uncharted territory. The room in which the workshop took place was built in the late 19th century as public baths and washhouses. It now houses staff and postgraduate offices, meeting and teaching rooms, and studios for MFA Fine Art and Curating students. The water tanks for the building provide a home to the Goldsmiths Centre for Contemporary Art. The room was up two flights of stairs, and we had to pass one of the entrances to the art studios, providing glimpses into art in the making. Grappling with a shared sense of uncertainty and fraudulence, as non-artists engaging in arts-based research, we carried on to find our allocated room. Our anxieties were intensified when we opened the door to find a freshly renovated space still harbouring the chemical scent of fresh paint, and our shoes squeaked upon the newly laid synthetic carpet. This L-shaped 
space, with an upper and lower level separated by a balustrade, had a stained-glass window, and on this late November day the space was bitterly cold. A tiny portable radiator struggled to provide sufficient heat to permeate the room, and many of us wore coats throughout the making. Despite spending over 10 years at Goldsmiths, Beckie had not been in this room before, and upon being allocated it by the central online booking system, had to set out on a search mission. It was not easy to find. This led to worry about whether participants would find the room (and whether they would want to stay if they did, given the cold!) so we hastily blue-tacked posters with arrows stuck onto walls to show the way. Like the bags, the location, the space, the architecture, and the temperature were all working on us in unexpected and uneasy ways.

Despite our knowledge of, and interest in, both how glitter behaves in unruly and uncontrollable ways, and how cultures and environments are always in relations of material affects (as discussed above), we nevertheless went to extraordinary lengths to attempt to manage the potential for contamination that the glitter posed. We attempted to control the agency of glitter so as not to damage or make a mess of the room. There were four large white oval tables in the room, each of which we covered with sheets of newspaper, as we also did with the domed power sockets that sat in the middle of them. At the end of the workshop, after the human participants had left, we began tidying and cleaning. Both the tables and the floor - with its new, clean carpet! - were infested with sprinklings of glitter. Beckie made multiple trips to the toilets on the ground floor to soak hand towels in the sinks (contributing yet more waste) to clean the tables while Jayne attempted to remove the glitter from the floor with a hand-held vacuum cleaner that Beckie had brought in from home. Despite Jayne's bent-double heroic efforts, it soon became clear that this was not a successful strategy, so Beckie then went on a trip around the campus - from the main reception to various buildings - trying to locate an industrial vacuum cleaner. She was returning without one when she bumped into a colleague who worked in the building where the workshop was held who told her where to find one. Equipped with his local knowledge, Beckie and an industrial vacuum cleaner made it down and then up two flights of stairs located in different parts of the building. This industrial strength vacuum cleaner proved much more efficient at eradicating the glitter (although not entirely). 


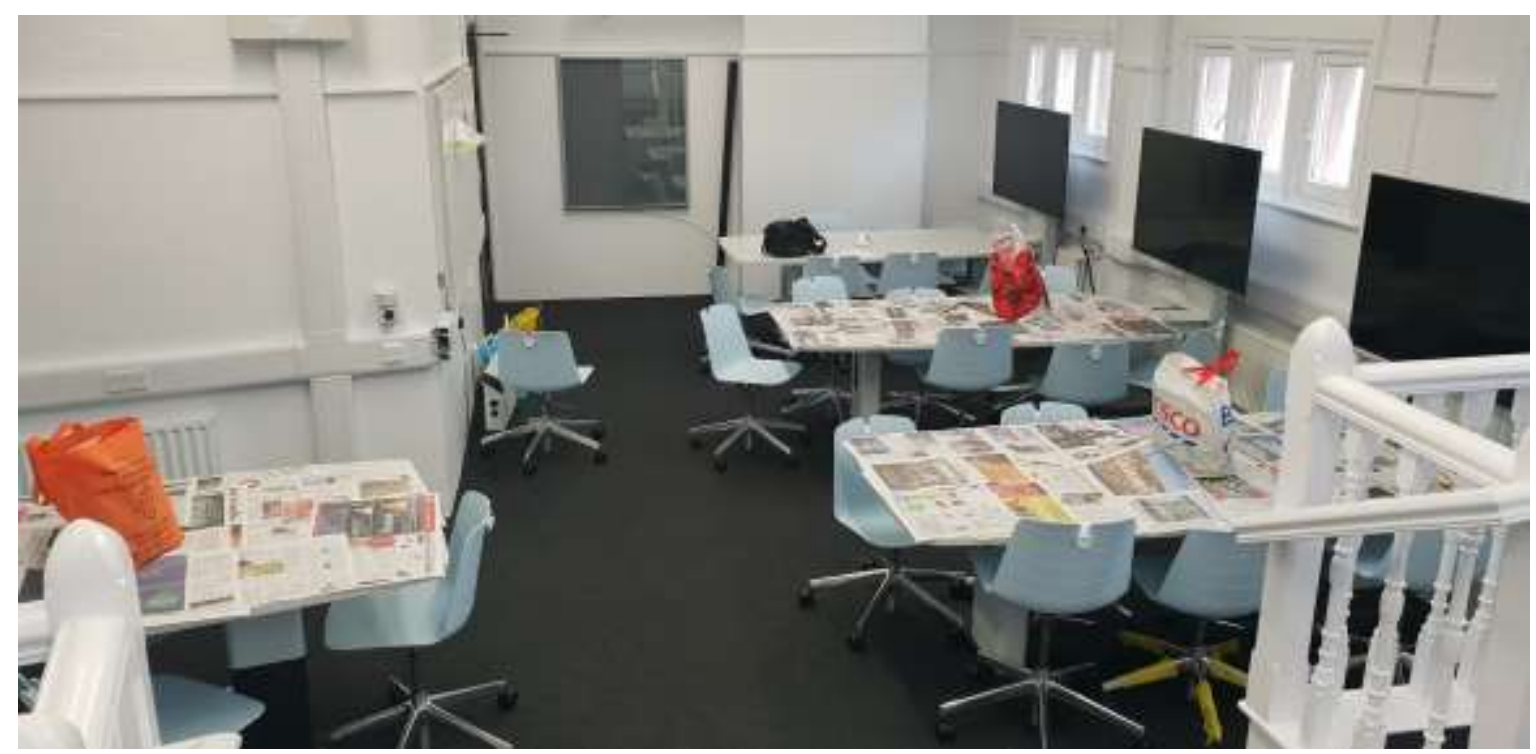

\section{Domestic Labour in the Academy: Acts of Response-ability}

We describe these aspects of setting up before and cleaning up after the workshop in some detail here to draw attention, again, to the affects and materialities of what the workshop generated and involved. In particular, explaining the labour that went into the workshop helps to explicate Ryan-Flood and Gill's (2010) call to make more apparent those aspects of the research (and teaching) process that tend to be made secret and silent. It is also a response to Gill's (2010) argument to link up macro-organisational and institutional practices and experiential and affective conditions in order to explore how they might be gendered, raced and classed. Part of the reason for us wanting to return the room to the state that it was in when we arrived was to ensure that the mess that we had made did not have to be dealt with by cleaning staff, who hadn't been involved in making it, and who we knew were paid less than us and worked in more precarious conditions. Following Barad (2007), we saw it as part of our feminist ethico-onto-response-ability. At the same time, our cleaning of the room made us reflect on whether other scholars, differently positioned, would feel the same response-ability to tidy the room, and to avoid others labouring more than necessary. We both laughed and expressed some indignation at this invisible labour, which we understood as gendered and classed, especially as the cleaning up took some time and we both felt the pressure to return home as soon as possible to fulfil our childcare responsibilities. As with the issue regarding the environmental affects/effects of glitter, raising this point regarding invisible labour does not solve it so much as make explicit very many political and ethical questions. It also raises questions concerning the distribution of care across different humans and non-humans.

\section{Doing (with) Glitter/Glitter's Doings}

As we have made clear, the purpose of this paper is not to make apparent what unfolded within the workshop in any great detail but rather to make visible and heard the affective 
charges, invisible labour and ethical dilemmas that working with glitter generates. Despite our anxieties and sensitivities surrounding the dilemmas that the workshop presented, there was nevertheless a buzz of excited anticipation hanging in the air. Arriving at a table that had hailed the human participants, the workshop took on another tempo. The room was a frenetic hive of activity, of materials and humans encountering each other, inviting curiosity, wonder, uncertainty. We were struck by just how many human participants were hailed to the 'natural' table, laden with mica glitter, leaves, seashells, pebbles and the cloth bag. This was predictable perhaps, given the concerns raised on social media and via email. Interestingly, though, the 'recycled' table, weighed down by second-hand, pre-loved, recycled, half-used and discarded glittering materials, failed to entice the same number of humans. In the meantime, the 'new' table was alive with political tension because the materials carried the scent of worldly irresponsibility (plastic pollution!), but it still managed to draw a sizeable human crowd.

As the workshop unfolded, and the groups of human participants rotated from table to table, it became evident that the 'natural' table persistently generated the greatest intensity and range of encounters. For example, some humans were magnetically drawn back to the table when they should have been stationed elsewhere. Others secretly hid their 'natural' creations so that they could not be worked on by the next cohort of human participants, knowing that they would ultimately be reunited at the conclusion of the workshop. The 'natural' materials, with the biodegradable mica glitter centre-stage, seemed to emit a magnetic air of virtuosity. Becoming-with materials at this table somehow became acts of wholesome goodness that simultaneously generated secretive and subversive behaviours.

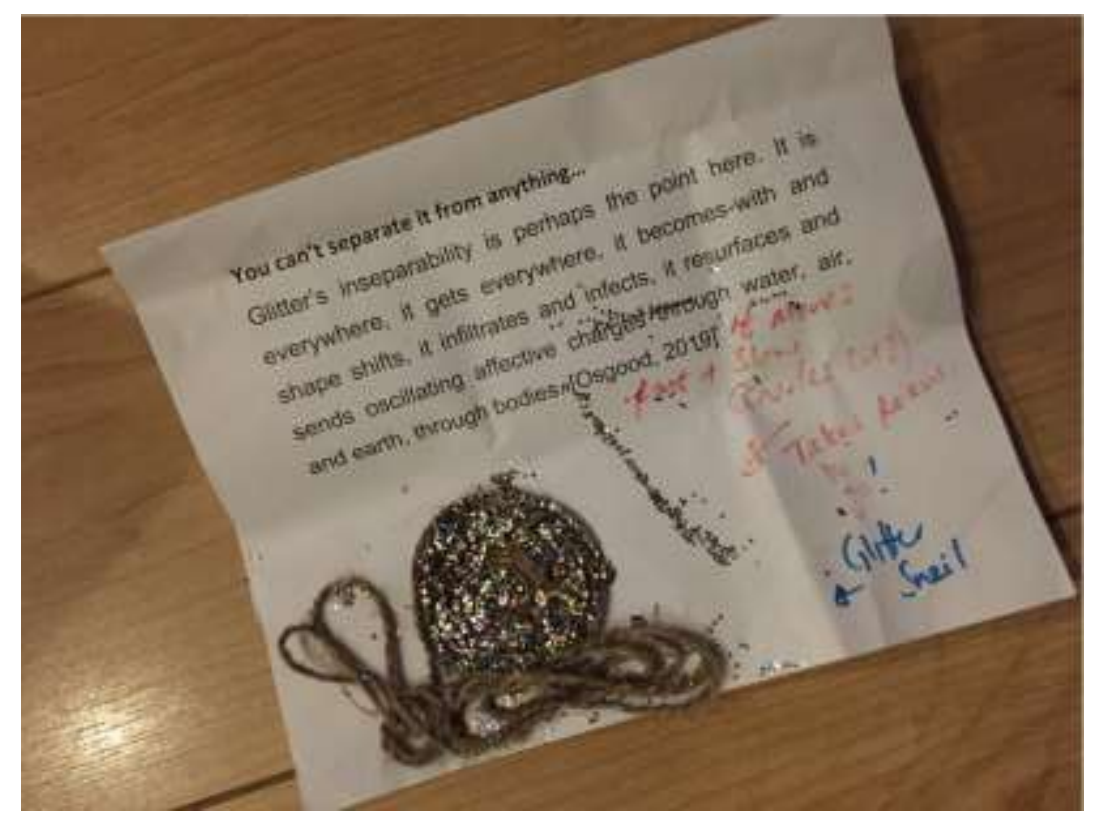

Glitter snail and photography by Monique Charles, one of the human participants of the workshop. 
The mica glitter was noticeably more tactile, more static, and less stiff, spiky and wilful than plastic glitter. It was also considerably quieter, duller, almost weightless, and possessed a relatively limited spectrum of colours. We noticed that human participants were more cautious, careful, and measured in how they handled the biodegradable glitter. This might be in part a consequence of its prohibitive cost - in the introduction to the workshop, in order to draw attention to issues of access to environmentally-friendly materials, Beckie noted that it had cost $f 50$ for two $100 \mathrm{~g}$ bags - but a similar ethic of care was also extended to the other 'natural' materials on the table. For example, a leaf bouquet, glittered stone, and leaf-string-garland were carefully crafted with a delicate touch not visible at the other tables. The pile of large brown-orange horse chestnut leaves were brittle and had changed texture several times on their journey from a front garden in north London, via the underground, to Beckie's office at the top of a tower building, back down in a lift, outside again in the rain and wind, then excavated from the depths of the cloth bag to the table top in the bitterly cold classroom. Leaves, mica glitter, Pritt-stick glue, academic quotes on A4 pages, and the busy hands of artistically-inclined scholars worked together to generate endless provocations that urged us to reflect on our ethical responsibilities as feminist academics engaged in world-making practices. As origami boats materialised to hold the glitter, and beautiful sculptures and artefacts took shape, we were struck by the care that the glitter and natural materials seemed to demand of the human in the making processes. Our subsequent, and on-going, dwelling upon what got made and how, and then what else gets generated as a consequence of materialdiscursivesemiotic making methodologies, presents us with disquieting and inconclusive questions. 

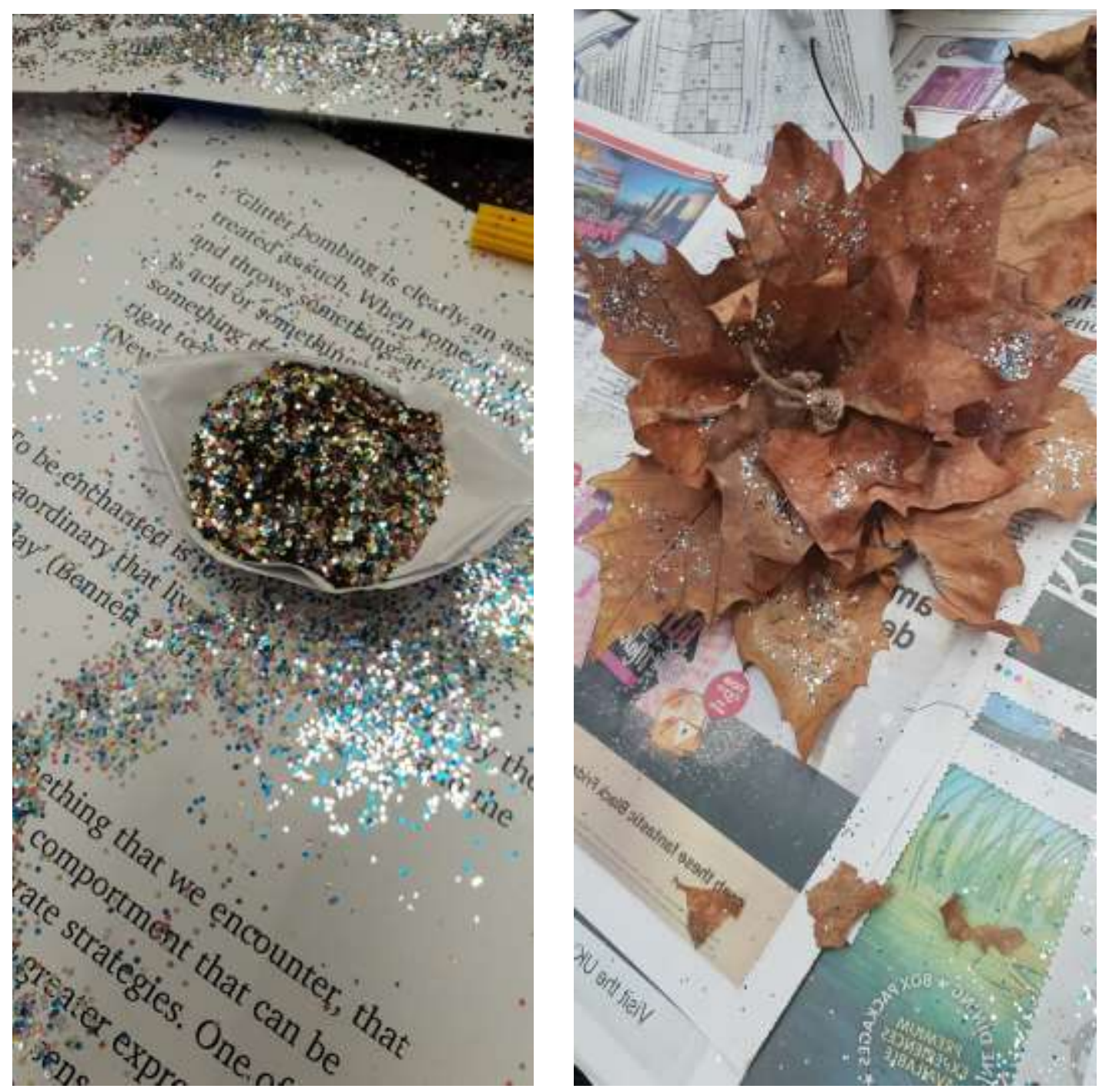

As mentioned, the 'recycled' table was visibly repellent to the human participants. Jayne had pilfered sparkly items from her eight-year-old daughter's arts and crafts box. Looking tired and out of place sitting atop the table in this classroom, these 'recycled' items enticed a lone human participant. Jayne felt saddened that these domestic artefacts had so little purchase against the 'natural' sparkle of the mica glitter, and the freshness of the new (plastic) glitter. Together the materials looked used, exhausted and thoroughly jaded - not 'preloved' as Jayne liked to imagine them. 'Recycled' should surely be no less virtuous than 'natural,' but it was certainly less appealing. The glitter on this table behaved in a tired fashion - congealed nail varnish, dried up glitter glue, lacklustre, sticky, stubborn and uncooperative. However, on account of our curation and choreography, all participants at some point during the workshop would encounter these unappealing and unruly materials. The lure of cooked meat and the call of star sequins worked together to materialise a gruesome 'glitter steak'. This creation was provocative in myriad inexplicable ways - 'just wrong,' as one person stated. 


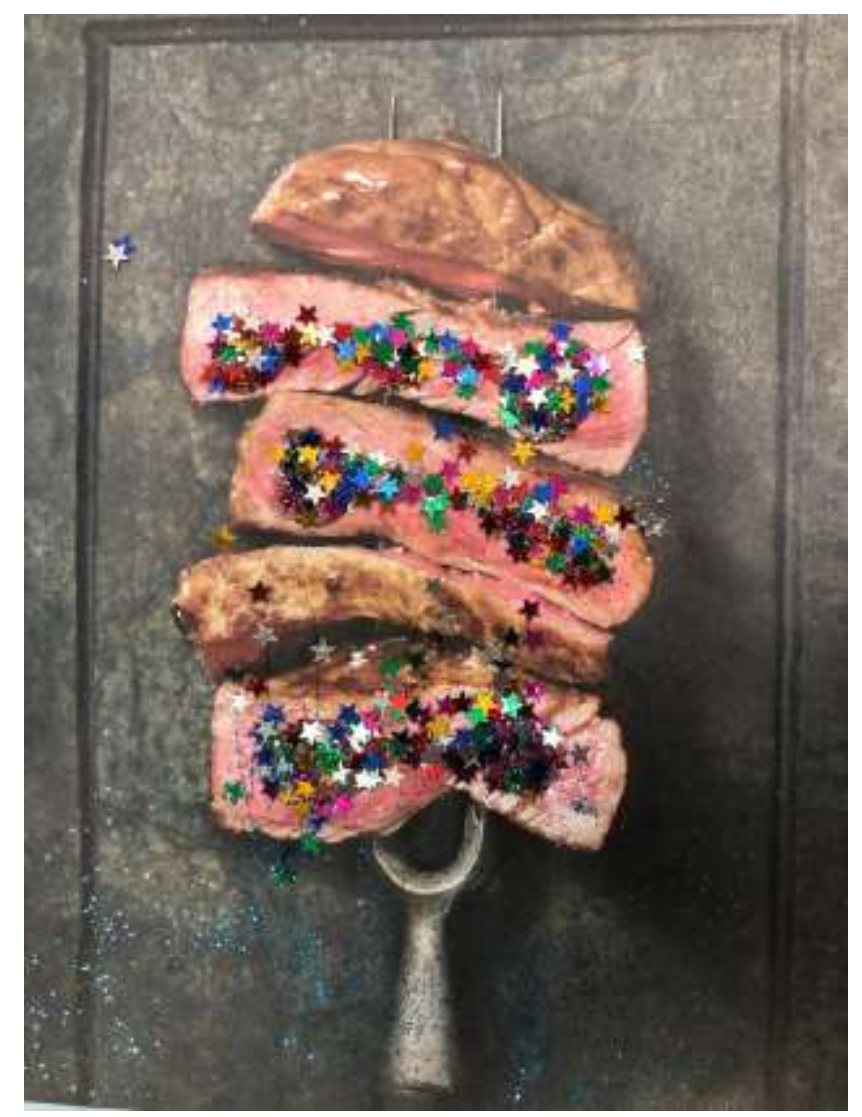

Interestingly, the 'new table' and the new materials seemed to generate the most lively human engagement; the same delicate, careful attention to the materials was noticeably absent. There was a perceptible sense of carefree abandonment, excessive consumption and careless dispersal of glitter at this table. The rate and pace of making appeared more frenzied and chaotic. The plastic glitter presented the humans with considerably more choice in terms of texture and the range of colours, and the glitter behaved in more familiar ways. The ease and reminiscence that this form of glitter evoked was sensed: we noticed that when people (ourselves included) were making at this table, it was much more excessive, frivolous and indulgent. The (microplastic) glitter behaved differently to the lightweight mica and to the congealed 'recycled' glitter. The new glitter refused to be manipulated. It was more lively and determined, but we knew what to expect from past encounters with commonly available glitter that behaved in this way. The glitter worked with the glue and newspaper in ways that defied human intentionality, and so creations become more emergent and unpredictable. There didn't appear to be the same moral imperative to use the glitter sparingly and with care - as was the case on the 'natural' table. A silver spillage of plastic glitter transformed an image of Teresa May (the UK Prime Minister at the time the workshop took place) into an unidentifiable, slightly menacing, hooded form. 


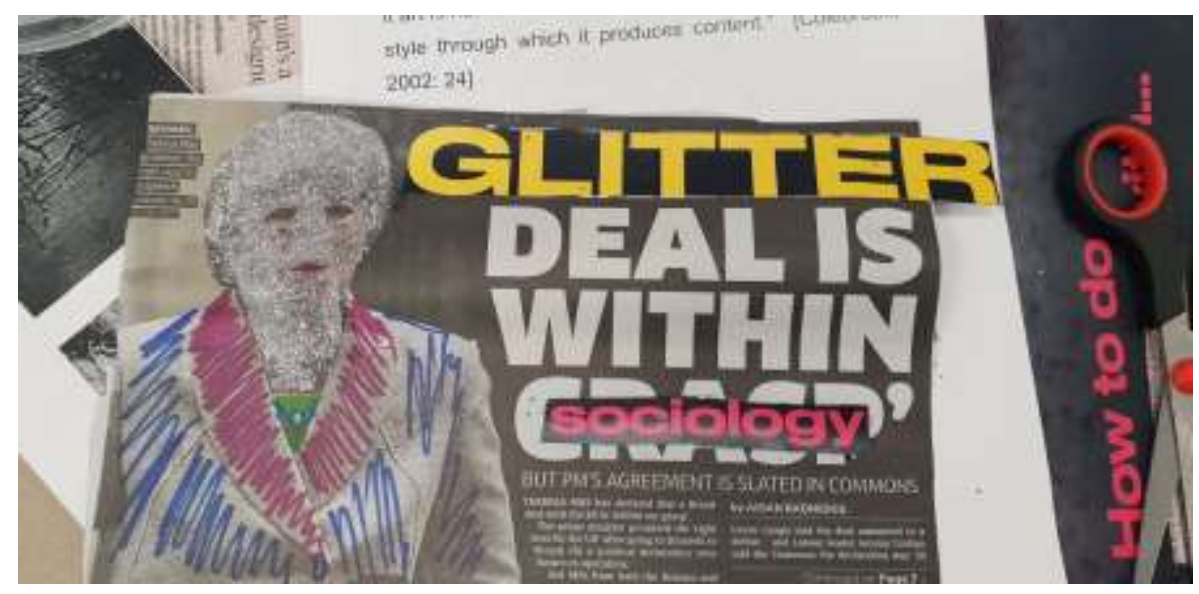

In a written reflection sent to us following their participation in the workshop ${ }^{3}$, Andre Fonseca described the making of this specific piece in terms of 'approach[ing] the materials in a more visual and curatorial process [...]. I choose to glue, cut, paint and cover [materials] with glitter [...] with specific colours. I discovered a pussy riot(esque) style and a baldessari(ist) way of covering people's faces with (as with Teresa May) glitter masks'. Interestingly, they explain these as 'pieces' rather than 'art works', 'since it's been done with an experimental character, distinct of the Art World context, perhaps more related to a Sociological one'. The 'pieces are assemblages of knowledge, irony (shades), associations, appropriations, personality, history, contemporaneity, theoretical references with practical instruments, filled up with queerness, feminism and childhood' (Fonseca, private communication). Given our feelings of fraudulence about working with arts-based methods and practices despite not being artists ourselves, as mentioned above, it is notable that this human participant distinguishes their pieces from 'the Art World context' by describing them as experimental assemblages - an understanding of the processes of making facilitated through the workshop that elicits more favourable affects in us.

At the end of the workshop, the groups were reunited with the table they had initially been drawn to. We spent some time curating the non-human materials and discussing the experiences with glitter and what was produced (not just materially but affectively, politically and ethically). Beckie and Jayne were concerned about the destiny of the materials that had participated in the workshop, perhaps especially given the concerns about the waste it would generate, and so human participants were invited to make a choice whether to exhibit, take home, or throw away their creations. After a fairly short debate, the consensus was to bin it! We initially felt disappointed at this, seeing some kind of exhibition as a means of being more careful with the materials that composed the creations. However, we later discussed how the same questions of what to do with the creations would have emerged following any exhibition, making clearer to us the never-ending, processual qualities of the ethical and political dilemmas we were experiencing. 


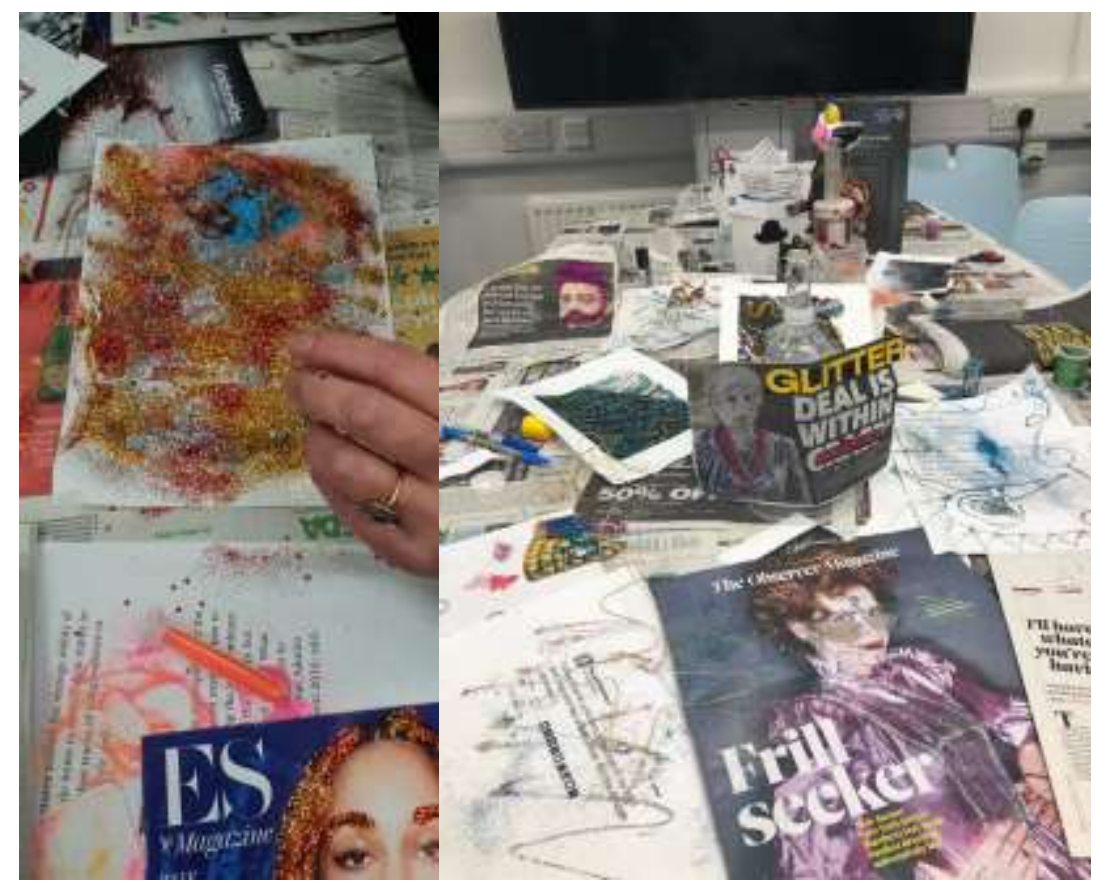

\section{In-conclusions about Response-ability and Pedagogy...}

In the first part of the contribution, we discuss how we designed the workshop by asking participants to seriousplay (Haraway, 2016) with glitter and explore its material and affective properties. We explored this aspect of the workshop through considering the relations between human and non-human participants, seeing agency as distributed across them, rather than as the preserve of the human. In so doing, we examined the ways in which materials attracted and appealed to participants, and in the latter part of the paper, we discussed how human and non-human participants worked together - although not equally in processes of making. Throughout, we opened out this discussion of what happened in the workshop itself to consider the material and affective questions that organising, running, cleaning up after and writing about the workshop produced. These include the invisible and domesticated labour of the feminist academic researcher, the curation and choreography of the workshop, and our heightened sensitivities after being called to account for our ethical intentions in working with glitter.

Through our focus on this one workshop, our aim in this paper has been to flesh out the ethics and politics of doing feminist new materialist research, including, crucially, an attention to what happens before and after as well as during. That is, in part we have written around the workshop, seeing the workshop as processual rather than as an opportunity to create outputs. This understanding of the workshop has come from our readings of and workings in feminist methodologies and feminist new materialisms, where the relationships between knowing and doing, theory and practice, epistemology and ontology, are thoroughly and productively entangled. The various political and ethical questions that have been raised by this workshop do not come with easy answers but 
instead require us to 'stay with the trouble', as Haraway (2016) encourages and we have noted with reference to Ryan-Flood and Gill's (2010) argument regarding the secrecy and silences of doing research. One way to conclude the paper might be to offer answers to the questions that we raised - should and could we have organised the workshop without profit-driven digital media, plastic glitter and bags, for example, or in a way that would not have rendered our labour invisible? However, we suggest that while answering such questions would offer some kind of closure, it would also shut down an attention to the ways in which a differently organised workshop would have generated its own questions. In this sense, we understand ethics, politics and care - and hence response-ability - as necessarily ongoing and processual. We want to be clear that this does not mean that we abandon our attempts to be response-able, nor to downplay the agentic power relations between humans and non-humans. Rather, it formulates ethics, politics and care as pedagogic.

Indeed, we see our attempt in this paper to document and follow some of this trouble as pedagogic. In asking, as we suggested at the opening of the paper, what we do with what glitter does, we take up Sara Ahmed's (2010: xvii) point that '[d]ifficulties are, as ever, pedagogic'. She argues:

feminist reflection on or about feminism is never simply self-reflection but reflection on the kinds of worlds in which we live. Feminist research in asking questions of itself, also asks us to reflect on what it means to do feminist research, which also means a commitment to consider the location of research, questions of power within research, as well as the limits of research ethics, whether defined negatively as not causing harm or positively in terms of promoting good. We learn that to make ethics difficult is to allow a different kind of conversation of the value of feminist work as well as the value of values (what is harm, what is good, for whom, when and where). And importantly, we think about feminist labour - about research as a form of work that in the Marxian sense is also praxis: a way of knowing that transforms what is known, or at least aims for such transformation (Ahmed 2010: xx).

Our encounters with glitter have been troubling and generative in equal measure. Attending to matter, and specifically glitter's doings within a choreographed workshop situation has enabled us to unearth a range of tentacular pedagogical possibilities. Working with what glitter does and dwelling upon what we do with what glitter does through exploring what it has taught us has presented us with surprises, as well as horribly familiar tropes around the invisible labour of the feminist researcher. We appreciate the pedagogical capacities that glitter possesses and conclude by arguing that when materiality is taken seriously it can generate new knowledges that lay the way for more liveable worlds (Haraway, 2016), worlds in which a heightened engagement with ethics, politics and care is central. 


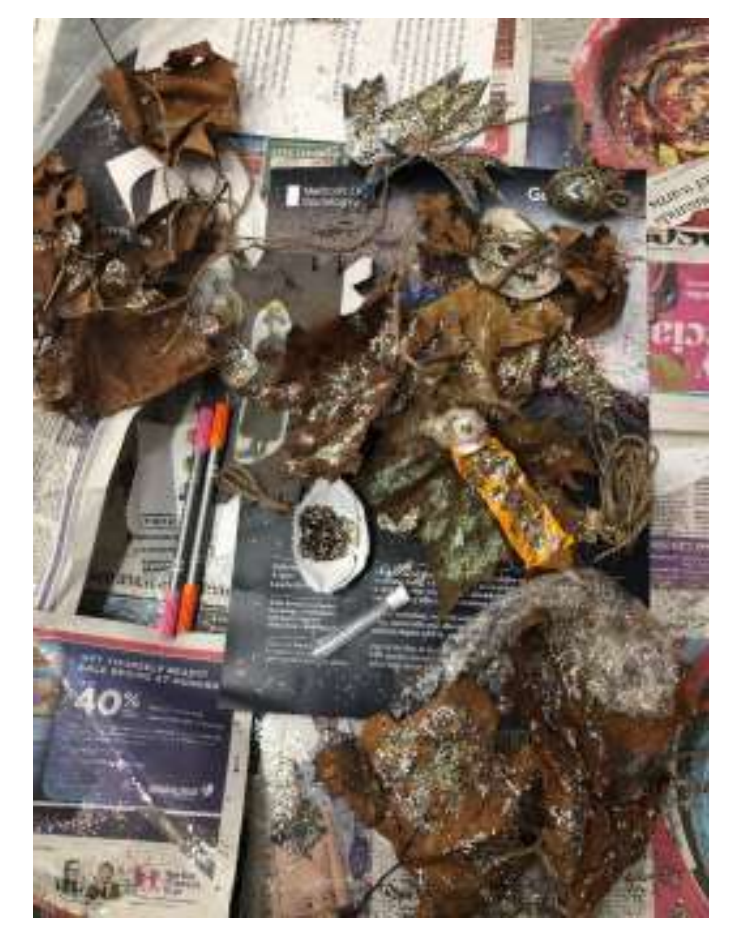

\section{References}

Ahmed, S (2010). 'Foreword.' In R. Ryan-Flood and R. Gill (eds.), Secrecy and silence in the research process: Feminist reflections (pp.xvi-xxi). London: Routledge. https://doi.org/10.1215/9780822388128

Barad, K. (2007). Meeting the universe halfway. Durham, NC: Duke University Press.

Coleman, R. (forthcoming). Glitterworlds: The future politics of a ubiquitous thing. London: Goldsmiths Press.

Coleman, R. (2008). A Method of Intuition: becoming, relationality, ethics. History of the Human Sciences, 21(4), 104-123. ISSN 0952-6951. https://doi.org/10.1177/0952695108095514

Gill, R. (2010). Breaking the Silence: The hidden injuries of neo-liberal academia. In R. RyanFlood and R. Gill (eds.), Secrecy and silence in the research process: Feminist reflections (pp. 228-244). London: Routledge.

Gunaratnam, Y. \& Hamilton, C. (2017). The wherewithal of feminist methods. Feminist Review, 115(1), 1-12. https://doi.org/10.1057/fr.2014.36

Haraway, D. (1994). A game of cat's cradle: Science studies, feminist theory, cultural studies. Configurations, 2(1), 59-71. https://doi.org/10.1353/con.1994.0009

Hickey-Moody, A.C. (2018). New materialism, ethnography, and socially engaged practice: Space-time folds and the agency of matter. Qualitative Inquiry, 1-9. https://doi.org/10.1177/1077800418810728

Hodgins, B.D. (Ed.) (2019). Feminist research for $21^{\text {st }}$ century childhoods: common worlds methods. London: Bloomsbury. https://doi.org/10.5040/9781350056602

Langford, R. (Ed.) (2019). Theorising feminist ethics of care in early childhood practice. London: Bloomsbury. 
Latimer, J. \& Miele, M. (2013). Naturecultures? Science, affect and the non-human. Theory, Culture and Society, 30(7/8), 5-31. https://doi.org/10.1177/0263276413502088

Moyles, H., Adams, S., \& Musgrove, A. (2002). Study of pedagogical effectiveness in early learning. London: HMSO.

Osgood, J. \& Robinson, K.H. (2019). Feminists researching gendered childhoods: Generative entanglements. London: Bloomsbury. https://doi.org/10.5040/9781474285810

Osgood, J. (2019). You can't separate it from anything: Glitter's doing as materialised figurations of childhood (and) art. In M. Sakr and J. Osgood, (eds.), Postdevelopmental approaches to childhood art (pp. 111-136). London: Bloomsbury.

Osgood, J. (forthcoming, 2019). Becoming a 'modest witness' in early childhood research. In C. Shulte, (Ed.), Ethics and research with young children: New perspectives. London: Bloomsbury.

Osgood, J. \& Andersen, C.E. (2019). A feminist new materialist experiment: exploring what else gets produced through encounters with children's news media. Contemporary Issues in Early Childhood. Children's News Media Special Issue, 20(4), 315-330. https://doi.org/10.1177/1463949119888482

Puig de la Bellacasa, M. (2017). Matters of care: Speculative ethics in more than human worlds. Minneapolis: University of Minnesota Press.

Renold, E. \& Ringrose, J. (2019). Jarring: Making phEmaterialist research practices matter. Accessed: https://maifeminism.com/introducing-phematerialism-feministposthuman-and-new-materialist-research-methodologies-in-education/

Ringrose, J., Warfield, K. \& Zarabadi, S. (2018). Feminist posthumanisms, new materialisms and education. London: Routledge.

Ryan-Flood, R. \& Gill, R. (2010) Introduction. In Ryan-Flood and R. Gill (eds.), Secrecy and silence in the research process: Feminist reflections (pp. 1-12). London: Routledge.

Skeggs, B. (ed.) (1995). Feminist cultural theory: Process and production. Manchester: Manchester University Press.

Stanley, L. \& Wise, S. (1982). Breaking out: Feminist consciousness and feminist research, London: Routledge and Kegan Paul.

\footnotetext{
${ }^{1}$ Vagazzling is the practice whereby crystals and other sparkly materials are glued to a shaved pubis mound (see Coleman, forthcoming, for more discussion).

2 These questions raise the point that Barad (2007) makes regarding the making and enforcing of boundary cuts in any project, and how these cuts are ethical and political. While developing an understanding of how agency is not only confined to humans - objects, tools and living creatures are all agentic - Barad's argument is that humans must take responsibility for the cuts they make. This is important and we seek to grapple with it here, alongside an argument that at the same time attempts to examine how the workshop generated the emergence of specific material and affective processes and onto-epistemological quandaries.

${ }^{3}$ We contacted all human participants of the workshop via the Eventbrite registration page to invite them to contribute to this paper by either providing images or reflections on the workshop: André Fonseca sent us written reflection and Monique Charles sent a photograph, both of which are included here. We also invited human participants to be credited as co-participants in the workshop: Louise Rondel and Ming Te Peng responded to this invitation. In this email to human participants, we also asked for their ethical approval to publish reflections, analysis and photographs of the workshop, without identifying them unless otherwise noted. We saw this as an important step to take given this Special Issue's focus on response-able research.
} 